\title{
A Constitutive Model of Particulate-Reinforced Composites Taking Account of Particle Size Effects and Damage Evolution
}

\author{
Keiichiro Tohgo, Yu Itoh and Yoshinobu Shimamura \\ Department of Mechanical Engineering, Shizuoka University \\ 3-5-1, Johoku, Naka-ku, Hamamatsu 432-8561, Japan
}

Corresponding author : Professor K. Tohgo

e-mail : tmktoug@ipc.shizuoka.ac.jp

Tel \& Fax : +81-53-478-1027 


\begin{abstract}
This paper deals with a constitutive model of particulate-reinforced composites which can describe the evolution of debonding damage, matrix plasticity and particle size effects on deformation and damage. An incremental damage model of particulate-reinforced composites based on the Mori-Tanaka's mean field concept has been extended to consider the particle size effects by using the Nan-Clarke's simple method. The particle size effect on deformation is realized by introducing dislocation plasticity for stress-strain relation of in-situ matrix in composites, and the particle size effect on damage is described by a critical energy criterion for particle-matrix interfacial debonding. For composites containing particles of various sizes, the effects of particle size distribution is incorporated into the model. Influence of debonding damage, particle size and particle volume fraction on overall stress-strain response of composites is discussed based on numerical results.
\end{abstract}

Keywords: A. Metal-matrix composites (MMCs); A. Particle-reinforcement; B. Debonding; C. Micro-mechanics

\title{
1. Introduction
}

The technique to improve mechanical performance of materials by dispersing particles in a matrix has been applied to ceramic-matrix, metal-matrix and polymer-matrix composites, and these materials are called particulate-reinforced composites. In particulate-reinforced composites, a variety of damage modes such as fracture of particles, interfacial debonding between particles and matrix, and cracking in matrix adjacent to hard particles develop from an early stage of deformation under monotonic and cyclic loads. These damage modes strongly affect mechanical performances such as stress-strain relation, tensile strength and fracture toughness [1-8]. It is well known that in particulate-reinforced metal-matrix composites mechanical performances also depend on particle size; the particle size is smaller, yield and flow stresses are more enhanced, while fracture toughness and ductility are often more reduced $[9,10]$. On the development of high-performance composites containing nano-particles, it is important to make clear the particle size effects and progress of damage in 
particulate-reinforced composites. In the present report, a constitutive model of particulate-reinforced composites taking account of the particle size effects and damage evolution has been proposed.

The influence of progressive damage on stress-strain relation of particulate-reinforced composites was studied with two schemes. Finite element analysis for a unit cell containing one particle in a matrix was widely applied to fracture or debonding of particles [11-18]. The unit cell analysis has an advantage to provide details of damage process in one particle. In the unit cell analysis, however, because it is assumed that all particles are in the same stage of damage process, we can not obtain overall stress-strain response of realistic composites containing intact particles and damaged particles. To overcome this problem, some modifications were proposed; for examples, the damaged cell model [12,14] and multi-particles cell model [15-18]. On the other hand, some micromechanics-based models were developed. In the micromechanics-based models, the damage evolution in composites can be described by transition of volume fraction from intact particles to damaged particles. Tohgo and Chou [19] and Tohgo and Weng [20] proposed an incremental damage model of particulate-reinforced composites taking into account plasticity of a matrix and progressive debonding damage of particles based on the Eshelby's equivalent inclusion method [21] and Mori-Tanaka's mean field concept [22]. This model was also extended to progressive cracking damage of reinforcements in discontinuously reinforced composites [23,24]. Chen et al. [25] developed a constitutive relation of particulate-reinforced viscoelastic-matrix composites with progressive debonding damage based on the same scheme. Matous [26] presented a constitutive relation of particulate-reinforced composites with debonding damage based on the transformation field analysis [27] and imperfect interface model [28] and applied it to damage analysis of glass-elastomer composites. Maire et al. [29] and Gonzalez and Llorca [30] separately proposed progressive cracking damage models of particulate-reinforced composites by applying an incremental self-consistent model developed by Corbin and Wilkinson [31] to the materials consisting of undamaged and damaged regions which are characterized by finite element analysis of unit cells. Ju and Lee [32] and Sun et al. [33] regarded the partially-debonded particles in composites as fictitious orthotropic inclusions 
without debonding according to Zhao and Weng [34], and proposed a progressive debonding damage model of particulate-reinforced composites based on the ensemble-volume averaging procedure. Some of the micromechanics-based models have an advantage of easy implementation into a finite element method. Tohgo et al. [35] and Tohgo and Itoh [36] introduced their damage model into a finite element method, and carried out damage analysis of a crack-tip field in particulate-reinforced composites. Based on the experimental and numerical results, they discussed roles of intact particles and debonding damage on toughening of composites.

The particle size effects on overall deformation behavior of composites come from the particle size effects on deformation and on damage. According to conventional continuum mechanics analysis of composites, magnitude of microscopic stress/strain depends on macroscopic stress/strain and microstructure, and distribution of microscopic stress/strain is uniquely determined on the basis of reference length of microstructure such as particle diameter or inter-particle distance. This means that the gradient in distributions of microscopic stress and strain is higher in composites with finer microstructure. In some composite systems, interphase with thickness of a characteristic length scale is created between particles and matrix. If mechanical properties of the interphase are different from those of the particles and matrix, the overall deformation behavior of composite depends on particle size because a volume fraction of the interphase increases with a decrease in particle size even if a fixed particle volume fraction. As the fracture strength of brittle materials is higher when the size of sample is smaller, the fracture and debonding of particles in composites is harder to occur on smaller sized particles. To describe these particle size effects in composites, it is tried to introduce the strain gradient plasticity for deformation behavior of the matrix, the interphase between particles and matrix, and the damage criterion considering the particle size effect on damage process into composites models. Niordson and Tvergaard [37], and Xue et al. [38] carried out unit-cell analysis for discontinuously reinforced composites by using a finite element method based on the strain gradient plasticity [39], and discussed the size effects of reinforcements on overall deformation behavior of composites. Nan and Clarke [40] extended the Nan-Yuan's effective medium approach [41] by introducing 
the particle size effects into stress-strain relation of in-situ matrix in composites and damage criterion of particles. Liu and Sun [42,43] and Jiang et al. [44] developed the micromechanics-based models of particle reinforced composites by taking account of the interphase between particles and matrix and discussed the particle size effect on deformation due to interphase. For the particle size effect on damage, the Weibull probability given in terms of particle stress and size is used to describe nucleation and progress of particle damage as in references $[14,16,18,2529,30]$.

In this paper, the incremental damage model by Tohgo, Chou and Weng [19,20] has been extended to consider the particle size effects by using the Nan-Clarke simple method [40]. Numerical analyses of stress-strain response under uniaxial tension are carried out for composites containing constant sized particles and for composites containing various sized particles. Influence of debonding damage, particle size and particle volume fraction on overall stress-strain response of composites is discussed based on the numerical results.

\section{Incremental damage theory}

Tohgo and Chou [19] developed an incremental damage model, which describes plasticity of a matrix and progressive debonding damage of particles in particulate-reinforced composites, based on the Eshelby's equivalent inclusion method [21] and Mori-Tanaka's mean field concept [22]. The incremental damage model of particulate-reinforced composites is briefly explained. For the model, the limitations and comparison with other models were already discussed in references $[19,20]$. The incremental constitutive relation $\left(\mathrm{d} \varepsilon_{i j}-\mathrm{d} \sigma_{i j}\right.$ relation) is described by the form decomposed into hydrostatic part ( $\mathrm{d} \varepsilon_{k k}-\mathrm{d} \sigma_{k k}$ relation) and deviatric part $\left(\mathrm{d} \varepsilon_{i j}{ }^{\prime}-\mathrm{d} \sigma_{i j}{ }^{\prime}\right.$ relation). $\mathrm{d} \sigma_{i j}$ and $\mathrm{d} \varepsilon_{i j}$ are incremental total stress and strain, $(1 / 3) \mathrm{d} \sigma_{k k},(1 / 3) \mathrm{d} \varepsilon_{k k}$ and $\mathrm{d} \sigma_{i j}{ }^{\prime}, \mathrm{d} \varepsilon_{i j}{ }^{\prime}$ are their hydrostatic and deviatric parts, respectively. The incremental total stress and strain are given by

$$
\mathrm{d} \sigma_{i j}=\mathrm{d} \sigma_{i j}{ }^{\prime}+\frac{1}{3} \mathrm{~d} \sigma_{k k} \delta_{i j} \quad, \quad \mathrm{~d} \varepsilon_{i j}=\mathrm{d} \varepsilon_{i j}{ }^{\prime}+\frac{1}{3} \mathrm{~d} \varepsilon_{k k} \delta_{i j}
$$

where $\delta_{i j}$ is the Kronecker delta. In the composite system elastic spherical particles are uniformly dispersed in an elastic-plastic matrix. 


\subsection{Properties of constituent materials}

Elastic incremental stress-strain relation of isotropic particles follows as

$$
\mathrm{d} \varepsilon_{k k}=\frac{1}{3 \kappa_{\mathrm{p}}} \mathrm{d} \sigma_{k k} \quad, \quad \mathrm{~d} \varepsilon_{i j}{ }^{\prime}=\frac{1}{2 \mu_{\mathrm{p}}} \mathrm{d} \sigma_{i j}{ }^{\prime}
$$

where $\kappa_{\mathrm{p}}$ and $\mu_{\mathrm{p}}$ are the bulk modulus and shear modulus of the particles. Elastic behavior of the matrix is also taken to be isotropic with the moduli $\kappa_{0}$ and $\mu_{0} . \kappa_{0}, \kappa_{\mathrm{p}}$ and $\mu_{0}, \mu_{\mathrm{p}}$ are related to the Young's moduli $E_{0}, E_{\mathrm{p}}$ and Poisson's ratios $v_{0}, v_{\mathrm{p}}$ by

$$
\kappa_{i}=\frac{E_{i}}{3\left(1-2 v_{i}\right)} \quad, \quad \mu_{i}=\frac{E_{i}}{2\left(1+v_{i}\right)} \quad, \quad i=0 \text { or } \mathrm{p}
$$

Elastic-plastic deformation of the matrix is described by the Prandtl-Ruess equation (the J2-flow theory), which is approximated by the following isotropic relation [19]:

$$
\mathrm{d} \varepsilon_{k k}=\frac{1}{3 \kappa_{0}} \mathrm{~d} \sigma_{k k} \quad, \quad \mathrm{~d} \varepsilon_{i j}{ }^{\prime}=\frac{1}{2 \mu_{0}^{\prime}} \mathrm{d} \sigma_{i j}{ }^{\prime}
$$

where

$$
\mu_{0}^{\prime}=\frac{\mu_{0}}{1+\frac{3 \mu_{0}}{H^{\prime}}} \quad, \quad v_{0}^{\prime}=\frac{v_{0}+\frac{\mu_{0}}{H^{\prime}}\left(1+v_{0}\right)}{1+2 \frac{\mu_{0}}{H^{\prime}}\left(1+v_{0}\right)}
$$

and $\mu_{0}{ }^{\prime}$ and $v_{0}{ }^{\prime}$ are the tangent shear modulus and tangent Poisson's ratio of the matrix under elastic-plastic deformation [45]. $H^{\prime}$ is the work-hardening ratio of the matrix:

$$
H^{\prime}=\frac{\mathrm{d} \sigma_{\mathrm{e}}}{\mathrm{d} \varepsilon_{\mathrm{e}}^{\mathrm{pl}}}
$$

where

$$
\begin{aligned}
& \sigma_{\mathrm{e}}=\left(\frac{3}{2} \sigma_{i j}{ }^{\prime} \sigma_{i j}{ }^{\prime}\right)^{1 / 2} \\
& \mathrm{~d} \varepsilon^{\mathrm{pl}} \mathrm{e}=\left(\frac{2}{3} \mathrm{~d} \varepsilon^{\mathrm{pl}}{ }_{i j} \mathrm{~d} \varepsilon^{\mathrm{pl}}{ }_{i j}\right)^{1 / 2}
\end{aligned}
$$

$\sigma_{\mathrm{e}}$ and $\mathrm{d} \varepsilon_{\mathrm{e}}{ }^{\mathrm{pl}}$ are the von Mises' equivalent stress and incremental equivalent plastic strain, respectively, and $\mathrm{d} \varepsilon^{\mathrm{pl}}{ }_{i j}$ is incremental plastic strain. Eq. (4) is strictly valid for monotonic proportional loading. 
In the composite system the stress and strain of the particles and matrix are represented with superscripts "p" and "0", respectively, and those of the composite are shown by symbols without superscript.

\subsection{Incremental constitutive relation of composite with progressive debonding damage}

A composite under consideration contains spherical particles with a finite concentration $f_{\mathrm{p} 0}$ in a matrix. Fig. 1(a) shows a schematic illustration of a composite in debonding damage process under high triaxial stress condition. The composite contains intact particles with volume fraction $f_{\mathrm{p}}^{\text {in }}$, fully-debonded particles with volume fraction $f_{\mathrm{p}}^{\text {fd }}$, and partially-debonded particles with volume fraction $f_{\mathrm{p}}^{\mathrm{pd}}[8,46]$. The stress of a particle is released by nucleation and progress of debonding damage, and eventually is completely released by full debonding. Even if not full debonding, if the particle loses almost whole stress, it can be regarded as a fully-debonded particle and acts as a void in the composite. The stress of intact particles in the micromechanics model is uniform and given by $\sigma^{\mathrm{p}} i j$, and average stresses of intact, fully-debonded and partially-debonded particles are approximately described by $\left\langle\sigma^{\mathrm{p}_{i j}}\right\rangle=k \sigma^{\mathrm{p}} i j$; where $k=1$ for intact particles, $k=0$ for fully-debonded particles, and $0<k<1$ for partially-debonded particles depending on debonding area. As the coefficient $k$ is related to volume fraction of each particle as in Fig. 1(c), the composite overall stress is given as follows:

$$
\begin{aligned}
\sigma_{i j} & =\left(1-f_{\mathrm{p} 0}\right)\left\langle\sigma_{i j}^{0}\right\rangle+\int_{0}^{f_{\mathrm{p} 0}} k \sigma^{\mathrm{p}}{ }_{i j} d f \\
& =\left(1-f_{\mathrm{p} 0}\right)\left\langle\sigma^{0}{ }_{i j}\right\rangle+f_{\mathrm{p}} \sigma^{\mathrm{p}_{i j}}
\end{aligned}
$$

where, $\left\langle\sigma^{0}{ }_{i j}\right\rangle$ is average stress of the matrix and

$$
f_{\mathrm{p}}=\int_{0}^{f_{\mathrm{p} 0}} k d f, \quad f_{\mathrm{d}}=f_{\mathrm{p} 0}-f_{\mathrm{p}}
$$

The composite shown in Fig. 1(a) can be regarded as a composite containing intact particles with $f_{\mathrm{p}}$ and voids with $f_{\mathrm{d}}$ as shown in Fig. 1(b). Then, the progress of damage in the composites is described by transition of a volume fraction from intact particles to voids and corresponding stress redistribution. There is limitation due to regarding fully-debonded particles as voids because the debonded particles can sustain the compressive stress. 
Therefore, the present model is confined to deformation and damage behavior under high triaxial stress condition for composites with relatively weak interface.

With the modeling as mentioned above, the composite is statistically homogeneous and macroscopically isotropic before and after damage. Fig. 2 illustrates the states before and after incremental deformation of the composite in damage process. Solid and open circles in the figure represent intact particles and voids (fully-debonded particles), respectively. In the composite, the microscopic stresses/strains in intact particles and matrix are generated due to material heterogeneity, in addition to the overall macroscopic stress/strain. The process of debonding damage in the composite can be simulated by the following assumptions.

(1) Debonding of particles is controlled by a critical value of particle stress because the interfacial stress between particles and matrix is described as a function of the particle stress $[25,47]$. In the present study, the critical stress is given by a critical energy criterion for particle-matrix interfacial debonding.

(2) During debonding, the stress of debonded particle is released and the site of particle is regarded as a void.

(3) A volume fraction of debonded particles turns into a void volume fraction, and progressive damage in the composite is expressed by a decrease in an intact particle volume fraction and an increase in a void volume fraction.

If the volume fraction of particles to be debonded in incremental deformation process is denoted by $\mathrm{d} f$, the volume fractions of intact particles and voids will change from $f_{\mathrm{p}}$ and $f_{\mathrm{d}}$ for the state before deformation (Fig. 2 (a)) to $f_{\mathrm{p}}-\mathrm{d} f$ and $f_{\mathrm{d}}+\mathrm{d} f$ for the state after deformation (Fig. 2 (b)), respectively. To describe deformation and damage of the composite in this incremental process, the Eshelby's equivalent inclusion method and Mori and Tanaka's mean field concept were applied for the heterogeneous body containing intact particles with $f_{\mathrm{p}}$-d $f$, voids with $f_{\mathrm{d}}$ and particles to be debonded with $\mathrm{d} f$ [19]. For this incremental deformation, the strain-stress relation of the composite is given as follows:

$$
\mathrm{d} \varepsilon_{k k}=\frac{1}{3 \kappa_{\mathrm{t}}} \mathrm{d} \sigma_{k k}+\frac{1}{3 \kappa_{\mathrm{d}}} \sigma_{k k}^{\mathrm{p}} \mathrm{d} f
$$




$$
\mathrm{d} \varepsilon_{i j}{ }^{\prime}=\frac{1}{2 \mu_{\mathrm{t}}} \mathrm{d} \sigma_{i j}{ }^{\prime}+\frac{1}{2 \mu_{\mathrm{d}}} \sigma_{i j}^{\mathrm{p}}{ }^{\prime} \mathrm{d} f
$$

where

$$
\begin{aligned}
& \kappa_{\mathrm{t}}=\frac{\kappa_{0}(1-\alpha) A_{\mathrm{h}}}{\left\{(1-\alpha)\left(1-f_{\mathrm{p}}-f_{\mathrm{d}}\right)+f_{\mathrm{d}}\right\}\left\{\kappa_{0}+\left(\kappa_{\mathrm{p}}-\kappa_{0}\right) \alpha\right\}+\kappa_{0}(1-\alpha) f_{\mathrm{p}}} \\
& \mu_{\mathrm{t}}=\frac{\mu_{0}(1-\beta) A_{\mathrm{d}}}{\left\{(1-\beta)\left(1-f_{\mathrm{p}}-f_{\mathrm{d}}\right)+f_{\mathrm{d}}\right\}\left\{\mu_{0}+\left(\mu_{\mathrm{p}}-\mu_{0}\right) \beta\right\}+\mu_{0}(1-\beta) f_{\mathrm{p}}} \\
& \kappa_{\mathrm{d}}=\frac{\kappa_{0}(1-\alpha) A_{\mathrm{h}}}{\kappa_{0}+\left(\kappa_{\mathrm{p}}-\kappa_{0}\right) \alpha} \\
& \mu_{\mathrm{d}}=\frac{\mu_{0}(1-\beta) A_{\mathrm{d}}}{\mu_{0}+\left(\mu_{\mathrm{p}}-\mu_{0}\right) \beta}
\end{aligned}
$$

and

$$
\begin{aligned}
& A_{\mathrm{h}}=\left(1-f_{\mathrm{p}}-f_{\mathrm{d}}\right)\left\{\kappa_{0}+\left(\kappa_{\mathrm{p}}-\kappa_{0}\right) \alpha\right\}+f_{\mathrm{p}} \kappa_{\mathrm{p}} \\
& A_{\mathrm{d}}=\left(1-f_{\mathrm{p}}-f_{\mathrm{d}}\right)\left\{\mu_{0}+\left(\mu_{\mathrm{p}}-\mu_{0}\right) \beta\right\}+f_{\mathrm{p}} \mu_{\mathrm{p}}
\end{aligned}
$$

$\left(\mathrm{d} \sigma_{k k}, \mathrm{~d} \sigma_{i j}\right)$ and $\left(\mathrm{d} \varepsilon_{k k}, \mathrm{~d} \varepsilon_{i j}{ }^{\prime}\right)$ are the incremental overall stress and strain of the composite, and $\left(\sigma_{k k}^{\mathrm{p}}, \sigma_{i j}^{\mathrm{p}}\right)$ denotes the current stress of the particles. With spherical particles and voids the constants $\alpha$ and $\beta$ follow from Eshelby's relations [21]:

$$
\alpha=\frac{1}{3} \frac{1+v_{0}}{1-v_{0}} \quad, \quad \beta=\frac{2}{15} \frac{4-5 v_{0}}{1-v_{0}}
$$

Incremental average stresses of the matrix and particles are given by

$$
\begin{aligned}
& \mathrm{d} \sigma_{k k}^{0}=\frac{\kappa_{0}+\left(\kappa_{\mathrm{p}}-\kappa_{0}\right) \alpha}{A_{\mathrm{h}}}\left(\mathrm{d} \sigma_{k k}+\sigma_{k k}^{\mathrm{p}} \mathrm{d} f\right) \\
& \mathrm{d} \sigma_{i j}^{0}{ }^{\prime}=\frac{\mu_{0}+\left(\mu_{\mathrm{p}}-\mu_{0}\right) \beta}{A_{\mathrm{d}}}\left(\mathrm{d} \sigma_{i j}{ }^{\prime}+\sigma_{i j}^{\mathrm{p}}{ }^{\prime} \mathrm{d} f\right) \\
& \mathrm{d} \sigma_{k k}^{\mathrm{p}}=\frac{\kappa_{\mathrm{p}}}{A_{\mathrm{h}}}\left(\mathrm{d} \sigma_{k k}+\sigma_{k k}^{\mathrm{p}} \mathrm{d} f\right) \\
& \mathrm{d} \sigma_{i j}^{\mathrm{p}}{ }^{\prime}=\frac{\mu_{\mathrm{p}}}{A_{\mathrm{d}}}\left(\mathrm{d} \sigma_{i j}{ }^{\prime}+\sigma_{i j}^{\mathrm{p}}{ }^{\prime} \mathrm{d} f\right)
\end{aligned}
$$

Furthermore, incremental average strains of the matrix, particles and voids are given by 


$$
\begin{aligned}
& \mathrm{d} \varepsilon_{k k}^{0}=\frac{\kappa_{0}+\left(\kappa_{\mathrm{p}}-\kappa_{0}\right) \alpha}{3 \kappa_{0} A_{\mathrm{h}}}\left(\mathrm{d} \sigma_{k k}+\sigma_{k k}^{\mathrm{p}} \mathrm{d} f\right) \\
& \mathrm{d} \varepsilon_{i j}^{0}{ }^{\prime}=\frac{\mu_{0}+\left(\mu_{\mathrm{p}}-\mu_{0}\right) \beta}{2 \mu_{0} A_{\mathrm{d}}}\left(\mathrm{d} \sigma_{i j}{ }^{\prime}+\sigma_{i j}^{\mathrm{p}}{ }^{\prime} \mathrm{d} f\right) \\
& \mathrm{d} \varepsilon_{k k}^{\mathrm{p}}=\frac{1}{3 A_{\mathrm{h}}}\left(\mathrm{d} \sigma_{k k}+\sigma_{k k}^{\mathrm{p}} \mathrm{d} f\right) \\
& \mathrm{d} \varepsilon_{i j}^{\mathrm{p}}{ }^{\prime}=\frac{1}{2 A_{\mathrm{d}}}\left(\mathrm{d} \sigma_{i j}{ }^{\prime}+\sigma_{i j}^{\mathrm{p}}{ }^{\prime} \mathrm{d} f\right) \\
& \mathrm{d} \varepsilon_{k k}^{\mathrm{d}}=\frac{\kappa_{0}+\left(\kappa_{\mathrm{p}}-\kappa_{0}\right) \alpha}{3 \kappa_{0} A_{\mathrm{h}}(1-\alpha)}\left(\mathrm{d} \sigma_{k k}+\sigma_{k k}^{\mathrm{p}} \mathrm{d} f\right)=\frac{\mathrm{d} \varepsilon_{k k}^{0}}{1-\alpha} \\
& \mathrm{d} \varepsilon_{i j}^{\mathrm{d}{ }^{\prime}=}=\frac{\mu_{0}+\left(\mu_{\mathrm{p}}-\mu_{0}\right) \beta}{2 \mu_{0} A_{\mathrm{d}}(1-\beta)}\left(\mathrm{d} \sigma_{i j}{ }^{\prime}+\sigma_{i j}^{\mathrm{p}}{ }^{\prime} \mathrm{d} f\right)=\frac{\mathrm{d} \varepsilon_{i j}^{0}{ }^{\prime}}{1-\beta}
\end{aligned}
$$

\subsection{Equivalent stress of the matrix in composite}

To describe the matrix plasticity, we need to estimate the von Mises' equivalent stress of the matrix. In the composite, as the matrix deforms heterogeneously, the microscopic stress and von Mises' equivalent stress are not uniform but distributed in the matrix. On the other hand, the present model gives the average microscopic stress of the matrix. Tohgo and Weng [34] proposed expression for average von Mises' equivalent stress of the matrix taking account of heterogeneous deformation in the composite. According to the theory, the equivalent stress $\sigma^{0}$ of the matrix in the composite before plastic deformation and damage is given by

$$
\left(\sigma_{\mathrm{e}}^{0}\right)^{2}=\frac{3 \mu_{0}}{1-f_{\mathrm{p} 0}}\left(2 U-f_{\mathrm{p} 0} \sigma_{i j}^{\mathrm{p}} \varepsilon_{i j}^{\mathrm{p}}\right)-\frac{3 \mu_{0}}{\kappa_{0}}\left(\sigma_{\mathrm{m}}^{0}\right)^{2}
$$

where, $\sigma^{0}{ }_{\mathrm{m}}\left(=(1 / 3) \sigma^{0}{ }_{k k}\right)$ is average hydrostatic stress of the matrix. $U$ is energy of a unit volume of the composite:

$$
U=\frac{1}{2} \sigma_{i j} \varepsilon_{i j}
$$

After the incremental deformation the equivalent stress of the matrix is estimated by $\sigma^{0}{ }_{\mathrm{e}}+\mathrm{d} \sigma_{\mathrm{e}}^{0}$, where $\sigma_{\mathrm{e}}^{0}$ and $\mathrm{d} \sigma^{0}{ }_{\mathrm{e}}$ denote current equivalent stress before the incremental 
deformation and its increment, respectively. In numerical analysis $\sigma^{0}{ }_{\mathrm{e}}$ is known and $\mathrm{d} \sigma^{0}$ is given by

$$
\mathrm{d} \sigma_{\mathrm{e}}^{0}=\frac{3 \mu_{0}}{\sigma_{\mathrm{e}}^{0}\left(1-f_{\mathrm{p}}-f_{\mathrm{d}}\right)}\left(\mathrm{d} U-\mathrm{d} R-f_{\mathrm{p}} \sigma_{i j}^{\mathrm{p}} \mathrm{d} \varepsilon^{\mathrm{p}}{ }_{i j}+\frac{1}{2} \mathrm{~d} f \sigma_{i j}^{\mathrm{p}} \varepsilon_{i j}^{\mathrm{p}}\right)-\frac{3 \mu_{0}}{\sigma^{0}{ }_{\mathrm{e}} \kappa_{0}} \sigma_{\mathrm{m}}^{0} \mathrm{~d} \sigma_{\mathrm{m}}^{0}
$$

where $\mathrm{d} U$ is incremental energy of the composite and $\mathrm{d} R$ is energy released by debonding damage:

$$
\begin{aligned}
& \mathrm{d} U=\sigma_{i j} \mathrm{~d} \varepsilon_{i j} \\
& \mathrm{~d} R=\frac{1}{2} \sigma_{i j} \mathrm{~d} \varepsilon_{i j}{ }^{\mathrm{dam}}
\end{aligned}
$$

where $\mathrm{d} \varepsilon_{i j}{ }^{\mathrm{dam}}$ is strain increment due to damage corresponding to the second terms in Eqs. (11) and (12).

If the matrix is in elastic-plastic state, the elastic moduli $\mu_{0}$ and $v_{0}$ in all equations in Sections 2.2 and 2.3 reduce to their elastic-plastic counterparts $\mu_{0}{ }^{\prime}$ and $\nu_{0}{ }^{\prime}$, respectively.

In deformation and damage behavior of particulate-reinforced composites, the particle size is an important factor in addition to the particle volume fraction. However, the above model based on the Eshelby's equivalent inclusion method and Mori-Tanaka's mean field concept can not describe the influence of particle size on elastic-plastic deformation.

\section{Implementation of particle size effects}

\subsection{Particle size effect on deformation}

In order to introduce particle size effects into the above incremental damage theory, the Nan-Clarke's simple method [40] has been used.

Particle size effect on deformation of the matrix is realized by introducing the dislocation plasticity for stress-strain relation of the in-situ matrix in composites. The stress-strain relation is given by Ramburg-Osgood relation as follows:

$$
\varepsilon_{\mathrm{e}}^{0}=\frac{\sigma_{\mathrm{e}}^{0}}{E_{0}}+\lambda \frac{\sigma_{0}^{0}}{E_{0}}\left(\frac{\sigma_{\mathrm{e}}^{0}}{\sigma_{0}^{0}}\right)^{1 / n}
$$

where, $\sigma_{\mathrm{e}}^{0}$ and $\varepsilon_{\mathrm{e}}^{0}$ are the equivalent stress and strain, $E_{0}, \sigma_{0}^{0}$ and $n$ are the Young's modulus, 
yield stress and work-hardening exponent, respectively, and $\lambda$ is material constant. In the conventional model, these material constants are determined for Eq. (35) to fit the uniaxial stress-strain relation of a bulk matrix material. Nan and Clarke [40] assumed that $\sigma_{0}^{0}$ is affected by particles in composites, and then modified as follows:

$$
\sigma_{0}^{0}=\left(\sigma_{0}^{0}\right)_{\mathrm{Bulk}}+\Delta \sigma_{0}^{0}
$$

where, $\left(\sigma_{0}^{0}\right)_{\text {Bulk }}$ is the yield stress for a bulk of the matrix material. $\Delta \sigma^{0}{ }_{0}$ expresses hardening of the matrix caused by particles in composites and is given by the dislocation plasticity as follows:

$$
\begin{aligned}
& \left(\Delta \sigma_{0}^{0}\right)^{2}=\left(\Delta \sigma_{\mathrm{OR}}^{0}+\Delta \sigma_{\mathrm{KIN}}^{0}\right)^{2}+\left(\Delta \sigma_{\mathrm{ISO}}^{0}\right)^{2}+\left(\Delta \sigma_{\mathrm{CTE}}^{0}\right)^{2} \\
& \quad=\left(\xi \mu_{0} b \sqrt{\frac{4 f_{\mathrm{p}}}{\pi d^{2}}}+\zeta \mu_{0} f_{\mathrm{p}} \sqrt{\frac{\varepsilon_{\mathrm{e}}^{0 \mathrm{p}}}{d}}\right)^{2}+\left(\eta \mu_{0} \sqrt{\frac{f_{\mathrm{p}} \varepsilon_{\mathrm{e}}^{0 \mathrm{p}} b}{d}}\right)^{2}+\left(\gamma \mu_{0} b \sqrt{\frac{6 \Delta T \Delta \theta f_{\mathrm{p}}}{b d\left(1-f_{\mathrm{p}}\right.}}\right)^{2}
\end{aligned}
$$

where, $\mu_{0}, b, \varepsilon^{0 \mathrm{p}}$ are the shear modulus, Burgers vector and equivalent plastic strain of the matrix, respectively, and $d$ is particle diameter. $\xi(=\sim 1.0), \eta(=\sim 0.4), \zeta(=\sim 2.0)$ and $\gamma(=$ 1.0) are constants. $\Delta \sigma_{\mathrm{OR}}^{0}$ is the Orowan stress for dislocation to pass through aligned particles, $\Delta \sigma_{\text {ISO }}^{0}$ and $\Delta \sigma_{\text {KIN }}^{0}$ are isotropic and kinematic contributions due to the effects of strain gradient plasticity related to the geometrically necessary dislocations for heterogeneous

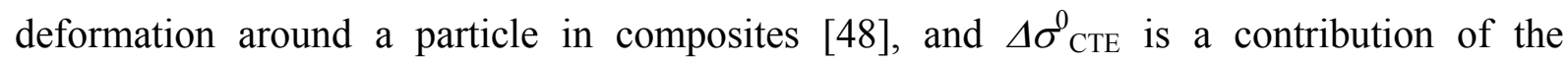
dislocations stored in fabrication due to thermal expansion mismatch $\Delta \theta$ and temperature change $\Delta T[49,50] . \Delta T$ is the difference between fabrication or heat treatment temperature and room temperature.

Contributions of the four kinds of hardening mechanisms seem to depend on composites. In the present investigation, for the contributions of each hardening mechanism, a nonlinear form as in Eq. (37) was assumed [51].

Kouzeli and Mortensen [10] reported the detailed experimental results on $\mathrm{Al}_{2} \mathrm{O}_{3}$ or $\mathrm{B}_{4} \mathrm{C}$ particulate-reinforced pure aluminum composites which supported the dislocation hardening of in-situ matrix depending on particle size or inter-particle distance. 


\subsection{Particle size effect on debonding damage}

In particulate-reinforced composites, it is well known that debonding damage of particles is easy to occur on large particles and hard to occur on small particles. To consider the particle size effect on damage, it is assumed that debonding damage is controlled by a critical energy criterion for particle-matrix interfacial debonding. Let us consider a particle with diameter of $d$ in a composite. The particle encounters debonding damage when the microscopic tensile stress of the particle reaches a critical value $\sigma_{\text {cr. }}^{\mathrm{p}}$. Since elastic strain energy stored in the particle is released and the void surface is created by full debonding damage, the following relation is obtained from energy balance during debonding process of a particle:

$$
\frac{\left(\sigma_{\mathrm{cr}}^{\mathrm{p}}\right)^{2}}{E_{\mathrm{p}}} d^{3} \propto \Gamma d^{2}
$$

where $\Gamma$ is the specific interface energy and $E_{\mathrm{p}}$ is the Young's modulus of the particle. Eq. (38) gives a proportional relationship between $\sigma_{\text {cr }}^{\mathrm{p}}$ and $\sqrt{E_{\mathrm{p}} \Gamma / d}$ [25]. In the present investigation, the following relation is used for the sake of simplicity.

$$
\sigma_{\mathrm{cr}}^{\mathrm{p}}=\sqrt{\frac{E_{\mathrm{p}} \Gamma}{d}}
$$

Furthermore $\Gamma$ means the critical strain energy release rate for particle-matrix interfacial debonding from a viewpoint of fracture mechanics. By introducing a critical stress intensity factor $K_{\mathrm{C}}$ defined by $\Gamma=K_{\mathrm{C}}{ }^{2} / E_{\mathrm{p}}$, Eq. (39) is described by

$$
\sigma_{\text {cr }}^{\mathrm{p}}=\frac{K_{\mathrm{C}}}{\sqrt{d}}
$$

As $\Gamma$ or $K_{\mathrm{C}}$ is uniquely given for combination of constituent materials in composites, Eqs. (39) and (40) represent the particle size effect for debonding damage.

By this implementation of particle size effects into the incremental damage theory, we need new parameters $\xi, \eta, \zeta$ and $\gamma$ in Eq. (35) and $\Gamma$ in Eq. (39) or $K_{\mathrm{C}}$ in equation (40). The values of $\xi, \eta, \zeta$ and $\gamma$ are roughly suggested by Nan and Clarks [40], and the value of $\Gamma$ or $K_{\mathrm{C}}$ would be basically obtained by fracture toughness tests for the interface between constituent 
materials. At present, since there are no data available for these parameters, they have to be determined by fitting so that the numerical stress-strain relations describe the experimental results. In the fitting procedure, by starting from the suggested values by Nan and Clarke for $\xi$, $\eta, \zeta$ and $\gamma$, and from the fracture toughness $K_{\mathrm{IC}}$ of particle material for $K_{\mathrm{C}}$, first $\xi, \eta, . \zeta$ and $\gamma$ can be determined from an early stage without damage of experimental stress-strain relation, and then $K_{\mathrm{C}}$ can be determined from a final stage with mach damage.

\section{Analysis of composites containing constant sized particles}

\subsection{Numerical procedure}

Numerical analyses were carried out on $\mathrm{SiC}$ particle reinforced aluminum (Al) alloy composite ( $\mathrm{SiC} / \mathrm{A} 356-\mathrm{T} 4)$ under uniaxial tension $[9,40]$. In uniaxial tension, the stress triaxiality defined by a ratio of hydrostatic stress to equivalent stress is about 0.33 and may be high enough to cause debonding damage of particles [35]. The present model is applied to obtain the relationship between the stress $\left(\sigma_{x x}\right)$ and strain $\left(\varepsilon_{x x}\right)$ in the tensile direction of the composite under uniaxial tension. The material properties of Al-alloy matrix were $E_{0}=70 \mathrm{GPa}$, $v_{0}=0.33,\left(\sigma^{0}{ }_{0}\right)_{\mathrm{Bulk}}=86 \mathrm{MPa}, n=0.212, \lambda=3 / 7$ and $b=0.283 \mathrm{~nm}$. The material properties of $\mathrm{SiC}$ particles were $E_{\mathrm{p}}=427 \mathrm{GPa}$ and $v_{\mathrm{p}}=0.17$. It was assumed that the composites contained constant sized particles with $15 \%$ of a particle volume fraction and then the particle size was changed in the analyses. The thermal expansion mismatch $\Delta \theta$ and temperature change $\Delta T$ for T4 heat treatment were $\theta=19.3 \times 10^{-6} /{ }^{\circ} \mathrm{C}$ and $\Delta T=520^{\circ} \mathrm{C}$. In Eq. (37), the values of $\xi, \eta, \zeta$ and $\gamma$ were assigned as 1.0, 0.4, 2.0 and 1.0, respectively, as in the Nan-Clarke's model for the comparison between the present model and the Nan-Clarke's model. In the composites with debonding damage, $\Gamma=15.8 \mathrm{~N} / \mathrm{m}\left(K_{\mathrm{C}}=2.6 \mathrm{MPa} \sqrt{\mathrm{m}}\right)$ was used for interfacial debonding between particles and matrix (see Section 5).

\subsection{Influence of particle size}

Fig. 3 shows the particle size effects on stress-strain relations of the composites without debonding damage and comparison between the present model and the Nan-Clarke's model [40]. If the particle size is larger than $50 \mu \mathrm{m}$, the stress-strain relations converge on a conventional result by the incremental damage model without particle size effects (ID model). 
However, if the particle size is smaller than $10 \mu \mathrm{m}$, the dislocation strengthening becomes dominant with decreasing particle size as shown in Fig. 3. Fig. 3 also shows that the present model predicts almost the same stress-strain relations as the Nan-Clarke's model. The present model is based on the Eshelby's equivalent inclusion method and Mori-Tanaka's mean field concept as a composite model and adopts the tangent modulus for matrix plasticity, while the Nan-Clarke's model is based on the effective medium approach and the secant modulus for matrix plasticity [40].

Fig. 4 shows the stress-strain relations of the composites in which the particle size is $0.5 \mu \mathrm{m}$ and only one term in Eq. (37) is considered. It is found from Fig. 4 that contributions of the dislocations stored in fabrication due to thermal expansion mismatch $\left(\Delta \sigma_{\mathrm{CTE}}^{0}\right)$ and the strain gradient in the matrix $\left(\Delta \sigma_{\text {ISO }}^{0}\right.$ and $\left.\Delta \sigma_{\text {KIN }}^{0}\right)$ are dominant as compared with that of the Orowan mechanism $\left(\Delta \sigma_{\text {OR }}^{0}\right)$. As shown in Eq. (37) and Fig. $4, \Delta \sigma_{\text {OR }}^{0}$ and $\Delta \sigma_{\text {CTE }}^{0}$ mainly contribute to an increase in the initial yield stress and $\Delta \sigma_{\text {ISO }}^{0}$ and $\Delta \sigma_{\text {KIN }}^{0}$ contribute to the plastic hardening in flow process. The contribution of each term of Eq. (37) on the stress-strain response depends on the constants $\xi, \eta, \zeta$ and $\gamma$. The characteristics of contribution as in Fig. 4 are useful in the determination of the values of $\xi, \eta, \zeta$ and $\gamma$.

\subsection{Influence of debonding damage}

In the composites with constant sized particles, Eq. (39) is spontaneously satisfied and debonding damage occurs on all particles. Numerical analyses of debonding damage in the composites with constant sized particles were carried out as follows. When Eq. (39) was satisfied at a certain deformation stage in the numerical analysis for strain increments, the progress of debonding damage was analyzed for damage increments under the strain increment of zero $\left(\mathrm{d} \varepsilon_{k k}=0, \mathrm{~d} \varepsilon_{i j}{ }^{\prime}=0\right)$ in Eqs. (11) and (12). After becoming a porous material of $f_{\mathrm{p}}=0$ and $f_{\mathrm{d}}=f_{\mathrm{p} 0}$ the numerical analysis was continued for strain increments. This numerical analysis corresponds to the finite element analysis of debonding damage process in a unit cell containing one particle.

Fig. 5 shows the composite macroscopic stress and microscopic average stresses in the particles and matrix against to the composite macroscopic strain obtained by the damage analysis of the composite with particles of $30 \mu \mathrm{m}$ in diameter. Before debonding damage the 
particles carry high stress. In the damage process, as the particle stress decreases to zero with progress of damage, the stresses of composite and matrix also decrease and the matrix goes back into elastic state. After that, the matrix yields plastically again for further deformation. Therefore, as shown in Fig. 5, a pop-in designated by a point $\mathrm{P}$ is obtained in the stress-strain relation. Because the composite becomes a porous material after debonding damage, the microscopic matrix stress is higher than the composite macroscopic stress.

Fig. 6 shows the influence of particle size on the stress-strain relations of the composites with debonding damage. The stress-strain relations of the matrix material and porous material containing voids of $15 \%$ are also shown in Fig. 6. The composite stress decreases down with debonding damage, and then after debonding damage the stress-strain relation of the composite is almost consistent with that of the porous material because the composite behaves as a porous material. The following two points are noticeable in Fig. 6. The particle size is smaller, the debonding damage is delayed more; this is obvious from Eq. (39). The stress-strain relation after debonding damage is slightly higher than that of the porous material; this might be caused by hardening of matrix material due to the particle size effects derived by the plastic deformation before debonding damage, and the hardening is more outstanding in a composite with smaller sized particles.

The step-wise stress decrease and pop-in on the stress-strain relations in Figs. 5 and 6 are the result of strict application of the deterministic criterion Eq. (39) to debonding damage in the composites with constant sized particles, and the similar results are also obtained in the finite element analysis of a unit cell analysis [11-13]. If the probabilistic Weibull criterion is used for the nucleation and progress of debonding damage, the smooth stress-strain relation can be obtained. The step-wise stress-strain relation due to the deterministic criterion may suggest that the nucleation of debonding damage can be a trigger of final fracture in such composites, or that the probabilistic criterion is more realistic than the deterministic criterion. Although the damage criterion may be open to discussion, in the present report we continue the numerical analysis based on the deterministic criterion Eq. (39) in the following section.

\section{Analysis of composites containing various sized particles}




\subsection{Numerical procedure}

Now, we consider composites containing various sized particles. It is assumed that distribution of particle size in a composite is given by probabilistic distribution $p(d)$ represented by number frequency. In the micromechanics-based model, the particles are uniformly and randomly distributed in the matrix and the position of each particle is not recognized, while the disturbance of stress field in matrix caused by particles is considered. As the size of the region disturbed by particles is related to the particle size, it is reasonable to regard the composite containing various sized particles as an assemblage of unit cells containing one particle with a constant particle volume fraction as shown in Fig. 7. Therefore, the influence of particles on macroscopic properties of the composite is not described by the number frequency $p(d)$, but volume frequency $p_{\mathrm{v}}(d)$. The volume frequency of particle $p_{\mathrm{v}}(d)$ is given by

$$
p_{\mathrm{v}}(d)=\frac{1}{\int d^{3} p(d) \mathrm{d} d} d^{3} p(d) .
$$

Consequently, some values $A$, such as the stress, strain, particle volume fraction and so on, of the composite containing various sized particles can be obtained by the following equation,

$$
A=\int p_{\mathrm{v}}(d) A(d) \mathrm{d} d,
$$

where $A(d)$ exhibits the values for a composite with constant sized particles of $d$.

Numerical analyses were carried out to discribe the Lloyd's experimental result [9] for composite (15vol\% SiC/A356-T4). The material properties used in the analyses were the same as those in Section 4. To describe the particle size effects, $\xi=1.8, \eta=0.4, \quad \zeta=2.0, \gamma=1.8$ and $\Gamma=15.8 \mathrm{~N} / \mathrm{m}\left(K_{\mathrm{C}}=2.6 \mathrm{MPa} \sqrt{\mathrm{m}}\right)$ were determined by the fitting procedure mentioned in Section 3. Number frequency of particles was assumed to follow the lognormal distribution,

$$
p(d)=\frac{1}{\sqrt{2 \pi} \delta d} \exp \left[-\frac{(\ln d-\phi)^{2}}{2 \delta^{2}}\right],
$$

where $\delta$ is the standard deviation and the mean particle diameter $\bar{d}$ is given by

$$
\bar{d}=\exp \left(\phi+\frac{\delta^{2}}{2}\right) \text {. }
$$

In Eq. (43), $\delta$ was set as 0.55 and $\phi$ were determined as 1.864 so as to be $\bar{d}=7.5 \mu \mathrm{m}$. Fig. 8 
shows the distribution of $p(d)$ and $p_{\mathrm{v}}(d)$. It can be seen that $p_{\mathrm{v}}(d)$ shifts toward larger particle side as compared with $p(d)$ and $\bar{d}=18.3 \mu \mathrm{m}$ for $p_{\mathrm{v}}(d)$. From Fig. 8, the composite was considered to contain the particles smaller than $70 \mu \mathrm{m}$ in diameter. In the numerical analysis, it was assumed that the composite contained the particles discreetly distributed in size from $0.175 \mu \mathrm{m}$ to $69.825 \mu \mathrm{m}$ with an interval of $0.35 \mu \mathrm{m}$ according to the lognormal distribution. Incremental analyses of the composites with constant sized particles were simultaneously carried out to obtain $A(d)$, and the values $A$ of the composite with various sized particles were obtained by substituting the numerical results $A(d)$ for each deformation stage into Eq. (42).

\subsection{Influence of particle size and debonding damage}

Fig. 9 shows the Lloyd's experimental results [9] and the numerical results for the stress-strain relations of the composite and matrix material under uniaxial tension. Firstly, from the comparison between the experimental result and a conventional result without particle size effects and debonding damage (ID model), the experimental result shows higher stress-strain relation; this means that the particle size effects should be considered. Secondly, as compared the experimental result with the numerical result taking account of particle size distribution and no debonding damage (ID-PSE-SD), both results show a good agreement with each other in an early stage of deformation, but the stress in the numerical result becomes higher than that in the experimental result as the deformation progresses. In Fig. 9, the numerical results for the composites with constant sized particles of number average diameter $7.5 \mu \mathrm{m}$ and volume average diameter $18.3 \mu \mathrm{m}$ and no debonding damage (ID-PSE-7.5 and ID-PSE-18.3) are also shown. When these results are compared with the result for the composite with particle size distribution, it is found that the composite with particle size distribution are well described by the composite with constant sized particles of volume average diameter.

As mentioned in Section 4.3, in the composite with constant sized particles the debonding damage controlled by Eq. (39) occurs simultaneously. On the other hand, in the composite with various sized particles the debonding damage occurs in turn from larger particles to smaller particles. For the composite with particle size distribution and debonding damage (ID-PSE-SD-DD) the stress-strain relation and progress of debonding damage 
represented by void volume fraction are shown in Fig. 9. Finally, on the numerical result of ID-PSE-SD-DD, as the debonding damage progresses, the stress-strain relation shifts from the result of ID-PSE-SD to lower side of the stress and then describes well the experimental result. Consequently, it is found that the experimental stress-strain relation of the SiC/A356-T4 can be described by the present model taking account of the particle size effects, particle size distribution and debonding damage. However, it is necessary to discuss more about the values of the constants in Eq. (37) and $\Gamma$ in Eq. (39) or $K_{\mathrm{C}}$ in Eq. (40).

Fig. 10 shows the influence of particle volume fraction on the stress-strain relations and progress of debonding damage of the composites with particle size distribution $(\bar{d}=7.5 \mu \mathrm{m}$ and $\delta=0.55$ ) and debonding damage. As shown in Fig. 10, in an early stage of deformation the reinforcing effect of intact hard particles is predominant and the stress-strain relation shifts upward with increasing particle volume fraction. However, with increasing deformation the stress-strain relation shifts downward due to the weakening effect of damaged particles, and this shift is more outstanding in the composite with higher particle volume fraction.

In the uniaxial tensile tests of a round bar specimen, a ductile material exhibits a plastic instability by neck formation near the maximum load, and the nominal stress at this event is referred to as the tensile strength. If the material is incompressible and its response is rate-independent, the onset of instability can be described by applying the Considere criterion to a true stress vs. true strain relation.

$$
\frac{\mathrm{d} \sigma_{x x}}{\mathrm{~d} \varepsilon_{x x}}=\sigma_{x x}
$$

Because the fracture of specimen is liable to occur before satisfying the Considere criterion on less ductile materials, the stress and strain obtained by the criterion correspond to upper bounds of the tensile strength and ductility (fracture strain). Open circular symbols in Fig. 10 show the points satisfying the Considere criterion on the stress-strain relations. It is suggested from Fig. 10 that with increasing particle volume fraction the tensile strength would increase slightly while the ductility would decrease considerably.

\section{Conclusions}


The incremental damage model of particulate-reinforced composites based on the Eshelby's equivalent inclusion method and Mori-Tanaka's mean field concept has been extended to consider the particle size effects by using the Nan-Clarke's simple method. In composites containing constant sized particles, the particle size is smaller, the dislocation strengthening is more dominant and debonding damage is harder to occur. In composites containing various sized particles, the debonding damage occurs from larger particles to smaller particles and the stress-strain relation shifts to lower side of stress. Experimental results of $\mathrm{SiC} / \mathrm{Al}$ composites can be described by the present model taking account of the particle size effects, particle size distribution and debonding damage.

The present model can describe elastic to elastic-plastic deformation of particulate-reinforced composites taking account of debonding damage, particle size effects and particle size distribution, and is also applicable to composites containing particles and voids and porous materials. Furthermore, it can be easily introduced into the finite element method which would be useful on strength evaluation and design of structures made of the composites.

\section{Acknowledgment}

The present work was supported by a Grant-in-Aid for Scientific Research ((B)(2) 15360050) from the Japan Society for the Promotion of Science (JSPS).

\section{References}

1. Bayha TD, Kilmer RJ, Wawner FE. The Fracture Characteristics of Al-9Ti/SiCp Metal Matrix Composites. Metall Trans A 1992;23A:16531662.

2. Llorca J, Martin A, Ruiz J, Elices M. Particulate fracture during deformation of a spray formed metal-matrix composite. Metall Trans A 1993;24A:1575-1588.

3. Whitehouse AF, Clyne TW. Cavity formation during tensile straining of particulate and short fibre metal matrix composites. Acta Metall Mater 1993;41:1701-1711.

4. Corbin SF, Wilkinson DS. Influence of matrix strength and damage accumulation on the mechanical response of a particulate metal matrix composite. Acta Metall Mater 
1994;42:1329-1335.

5. Caceres CH, Griffiths JR. Damage by Cracking of Silicon Particles in an Al-7Si-0.4Mg Casting Alloy. Acta Mater 1996;44:25-33.

6. Kiser MT, Zok FW, Wilkinson DS. Plastic flow and fracture of a particulate metal matrix composite. Acta Mater 1996;44:3465-3476.

7. Hartingsveldt EAA, Aartsen JJ. Interfacial debonding in polyamide-6/glass bead composites. Polymer 1989;30:1984-1991.

8. Tohgo K, Mochizuki M, Ishii H. Incremental damage theory and its Application to glass-particle-reinforced Nylon 66 composites. Int J Mech Sci 1998;40:199-213.

9. Lloyd DJ. 1994. Particle reinforced aluminium and magnesium matrix composites. Int Mater Rev 1994;39(1):1-23.

10. Kouzeli M, Mortensen A. Size dependent strengthening in particle reinforced aluminum. Acta Mater 2002;50:39-51.

11. Needleman AA. Continuum model for void nucleation by inclusion debonding. ASME J Appl Mech 1987;54:525-531.

12. Bao G. Damage due to Fracture of Brittle Reinforcements in a Ductile Matrix. Acta Metall Mater 1992;40:2547-2555.

13. Finot M, Shen YL, Needleman A, Suresh S. Micromechanical modeling of reinforcement fracture in particle-reinforced metal-matrix composites. Metall Mater Trans A 1994;25A:2403-2420.

14. Brockenbrough JR, Zok FW. On the role of Particle Cracking in Flow and Fracture of Metal Matrix Composites. Acta Metall Mater 1995;43:11-20.

15. Llorca J, Segurado J. Three-dimensional multiparticle cell simulation of deformation and damage in sphere-reinforced composites. Mater Sci Eng 2004;A365:267-274.

16. Eckschlager A, Han W, Böhm HJ. A unit cell model for brittle fracture of particles embedded in a ductile matrix. Comput Mater Sci 2002;25:85-91.

17. Segurado J, Llorca J. A computational micromechanics study of the effect of interface decohesion on the mechanical behavior of composites. Acta Mater 2005;53:4931-4942.

18. Segurado J, Llorca J. Computational micromechanics of composites: The effect of 
particle spatial distribution. Mech Mater 2006;38:873-883.

19. Tohgo K, Chou TW. Incremental theory of particulate-reinforced composites including debonding damage. JSME Int J 1996;39:389-397.

20. Tohgo K, Weng GJ. A progressive damage mechanics in particle-reinforced metal-matrix composites under high triaxial tension. ASME J Eng Mater Technol 1994;116:414-420.

21. Eshelby JD. The determination of the elastic field of an ellipsoidal inclusion, and related problems. Proc R Soc London 1957;A241:376-396.

22. Mori T, Tanaka K. Average stress in matrix and average elastic energy of materials with misfitting inclusions. Acta Metall 1973;21:571-574.

23. Cho YT, Tohgo K, Ishii H. Load carrying capacity of a broken ellipsoidal inhomogeneity. Acta Mater 1997;45:4787-4795.

24. Tohgo K, Cho YT. Theory of reinforcement damage in discontinuously-reinforced composites and its application. JSME Int J 1999;42:521-529.

25. Chen JK, Huang ZP, Mai YW. Constitutive relation of particulate-reinforced viscoelastic composite materials with debonded microvoids. Acta Mater 2003;51:3375-3384.

26. Matous K. Damage evolution in particulate composite materials. Int J Solids Struct 2003;40:1489-1503.

27. Dvorak GJ, Benveniste Y. On transformation strains and uniform fields in multiphase elastic media. Proc R Soc London 1992;A432:291-310.

28. Hashin Z. The spherical inclusion with imperfect interface. ASME J Appl Mech 1991;58:444-449.

29. Maire E, Wilkinson DS, Embury JD, Fougeres R. Role of damage on the flow and fracture of particulate reinforced alloys and metal matrix composites. Acta Mater 1997;45:5261-5274.

30. Gonzalez C, Llorca J. A self-consistent approach to the elasto-plastic behaviour of two-phase materials including damage. J Mach Phys Solids 2000;48:675-692.

31. Corbin SF, Wilkinson DS. The influence of particle distribution on the mechanical response of a particulate metal matrix composite. Acta Metall Mater 1994;42:1311-1318.

32. Ju JW, Lee HK. A micromechanical damage model for effective elastoplastic behavior of 
partially debonded ductile matrix composites. Int J Solids Struct 2001;38:6307-6332.

33. Sun LZ, Ju JW, Liu HT. Elasticplastic modeling of metal matrix composites with evolutionary particle debonding. Mech Mater 2003;35:559-569.

34. Zhao YH, Weng GJ. Transversely isotropic moduli of two partially debonded composites. Int J Solids Struct 1997;34:493-507.

35. Tohgo K, Fukuhara D, Hadano A. The influence of debonding damage on fracture toughness and crack-tip field in glass-particle-reinforced Nylon 66 composites. Comp Sci Tech 2001;61:1005-1016.

36. Tohgo K, Itoh T. Elastic and elastic-plastic singular fields around a crack-tip in particulate-reinforced composites with progressive debonding damage. Int J Solids Struct $2005 ; 42: 6566-6585$.

37. Niordson CF, Tvergaard V. Nonlocal plasticity effects on the tensile properties of a metal matrix composite. Euro J Mech A/ Solids 2001;20:601-613.

38. Xue Z, Huang Y, Li M. Particle size effect in metallic materials: A study by the theory of mechanism-based strain gradient plasticity. Acta Mater 2002;50:149-160.

39. Fleck NA, Muller GM, Ashby MF, Hutchinson JW. Strain gradient plasticity: theory and experiment. Acta Metall Mater 1994;42:475-487.

40. Nan CW, Clarke DR. The influence of particle size and particle fracture on the elastic/plastic deformation of metal matrix composites. Acta mater 1996;44:3801-3811.

41. Nan CW, Yuan RZ. Multiple-scattering solution to nonlinear mechanical properties of binary elastic-plastic composite media. Phys Rev B 1993;48:3042-3047.

42. Liu HT, Sun LZ. Multi-scale modeling of elastoplastic deformation and strenthening mechanism in aluminum-based amorphous nanocomposites. Acta Mater $2005 ; 53: 2693-2701$.

43. Liu HT, Sun LZ. A micromechanics-based elastoplastic model for amorphous composites with nanoparticle interactions. J Appl Mech, ASME 2008;75:031009-1-10.

44. Jiang YP, Tohgo K, Shimamura Y. A micro-mechanics model for composites reinforced by regularly distributed particles with an inhomogeneous interphase. Comput Mater Sci 2009;46:507-515. 
45. Berveiller M, Zaoui A. An Extension of the Self-Consistent Scheme to Plastically-Flowing Polycrystals. J Mech Phys Solids 1979;26:325-344.

46. Babout L, Maire E, Buffiere JY, Fougeres R. Characterization by X-ray computed tomography of decohesion, porosity growth and coalescence in model metal matrix composites. Acta Mater 2001;49:2055-2063.

47. Tandon GP, Weng GJ. Stress distribution in and around spheroidal Inclusions and voids at finite concentration. ASME J Appl Mech 1986;53:511-518.

48. Brown LM, Stobbs WM. The work-hardening of copper-silica, V. Equilibrium plastic relaxation by secondary dislocations. Phil Mag 1976;34:351-372.

49. Arsenault RJ, Shi N. Dislocation generation due to differences between the coefficients of thermal expansion. Mater Sci Eng 1986;81:175-187.

50. Arsenault RJ, Wang L, Feng CR. Strengthening of composites due to microstructural changes in the matrix. Acta Metall Mater 1991;39:47-57.

51. Clyne TW, Withers PJ. An Introduction to Metal Matrix Composites. Cambridge University Press, Cambridge. 1993. p.86-94. 


\section{Figure Caption}

Fig. 1 Schematic illustrations of a composite in debonding damage process and a composite in micromechanics model.

Fig. 2 States of a composite undergoing damage process before and after incremental deformation. $\mathrm{d} f_{\mathrm{p}}$ is a volume fraction of the particles debonded in the incremental process.

Fig. 3 Particle size effects on stress-strain relation of the composites and comparison between the present model and Nan-Clarke's model. ID model shows Tohgo-Chou-Weng's model without particle size effects.

Fig. 4 Influence of each term in dislocation plasticity on stress-strain relation of the composite with particle size of $0.5 \mu \mathrm{m}$.

Fig. 5 Composite stress and microscopic stresses of the particles and matrix as functions of composite strain on the composite with debonding damage.

Fig. 6 Particle size effects on stress-strain relation of the composites with debonding damage.

Fig. 7 Composite containing particles with size distribution.

Fig. 8 Lognormal distribution for number frequency $p(d)$ and volume frequency $p_{\mathrm{v}}(d)$ of the particle size distribution.

Fig. 9 Comparison of stress-strain relations between the predictions and Lloyd's experimental result for a composite (15vol\%SiC/A356-T4).

ID model: Tohgo-Chou-Weng's model.

ID-PSE-7.5 and ID-PSE-18.3: models considering particle size effects for composites with particle size of $7.5 \mu \mathrm{m}$ and $18.3 \mu \mathrm{m}$, respectively.

ID-PSE-SD: a model considering particle size effects and size distribution.

ID-PSE-SD-DD: a model considering particle size effects, size distribution and debonding damage.

Fig. 10 Influence of particle volume fraction on stress-strain relations and progress of debonding damage of the composites with particle size distribution $(\bar{d}=7.5 \mu \mathrm{m}$ and $\delta$ $=0.55)$ and debonding damage. 

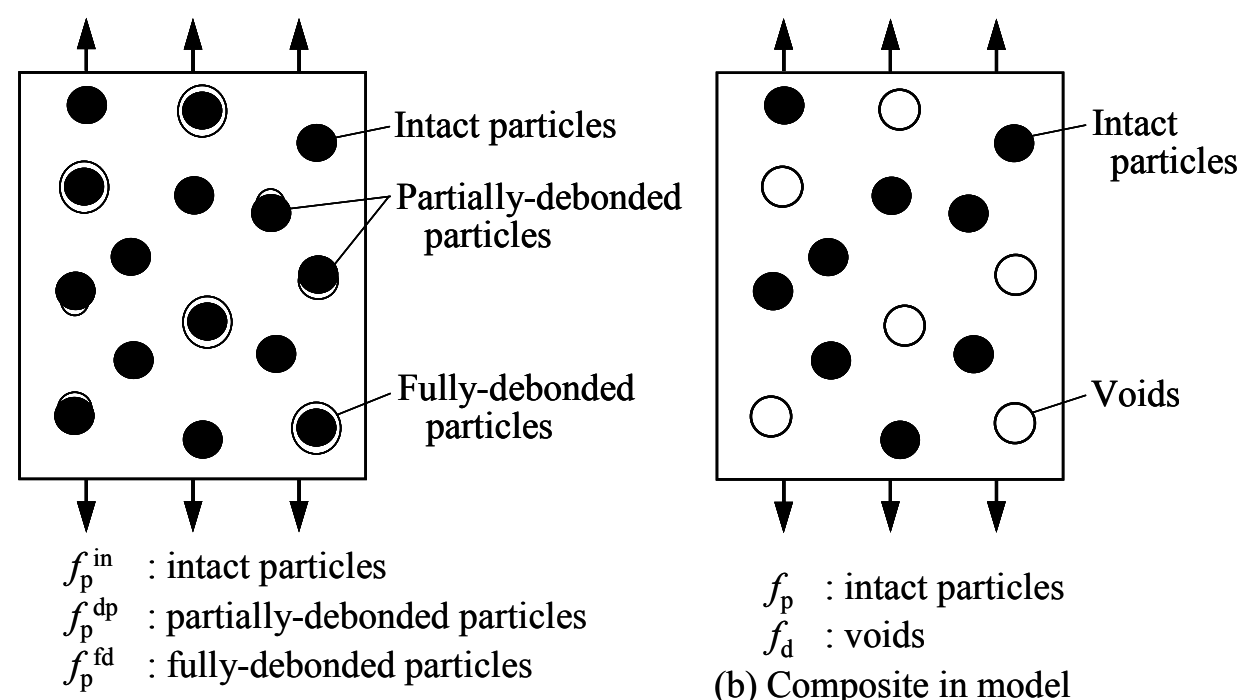

(a) Composite in damage process

(b) Composite in model

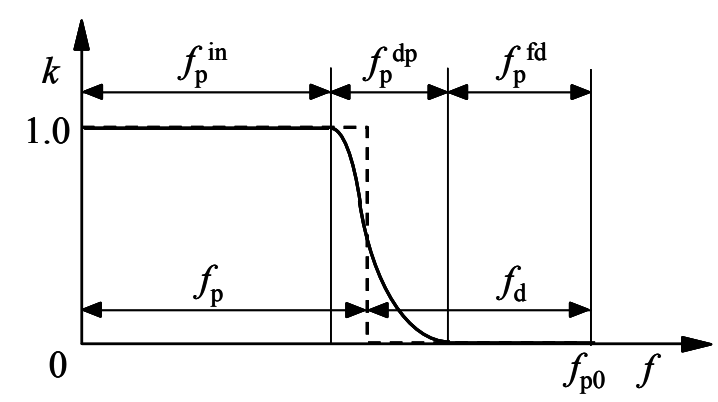

(c) Coefficient $k$ in $\left\langle\sigma_{i j}^{\mathrm{p}_{i j}}\right\rangle=k \sigma^{\mathrm{p}}$ ij for intact, partially-debonded and fully-debonded particles.

Fig. 1 Schematic illustrations of a composite in debonding damage process and a composite in micromechanics model. 

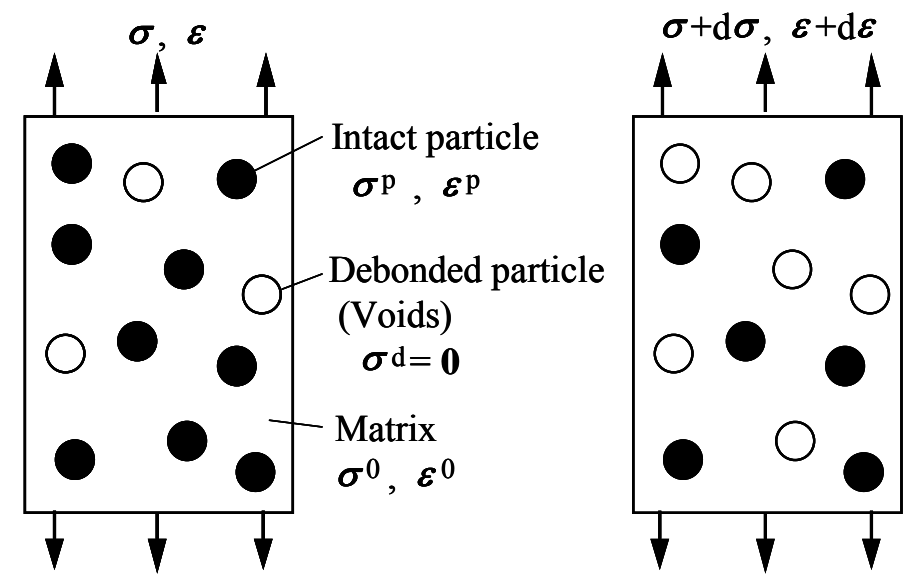

Volume fractions of intact particles : $\quad f_{\mathrm{p}}$ debonded particles: $f_{\mathrm{d}}$

Volume fractions of intact particles : $\quad f_{\mathrm{p}}-\mathrm{d} f$ debonded particles : $f_{\mathrm{d}}+\mathrm{d} f$

(a) Before incremental deformation

(b) After incremental deformation

Fig. 2 States of a composite undergoing damage process before and after incremental deformation. $\mathrm{d} f_{\mathrm{p}}$ is a volume fraction of the particles debonded in the incremental process.

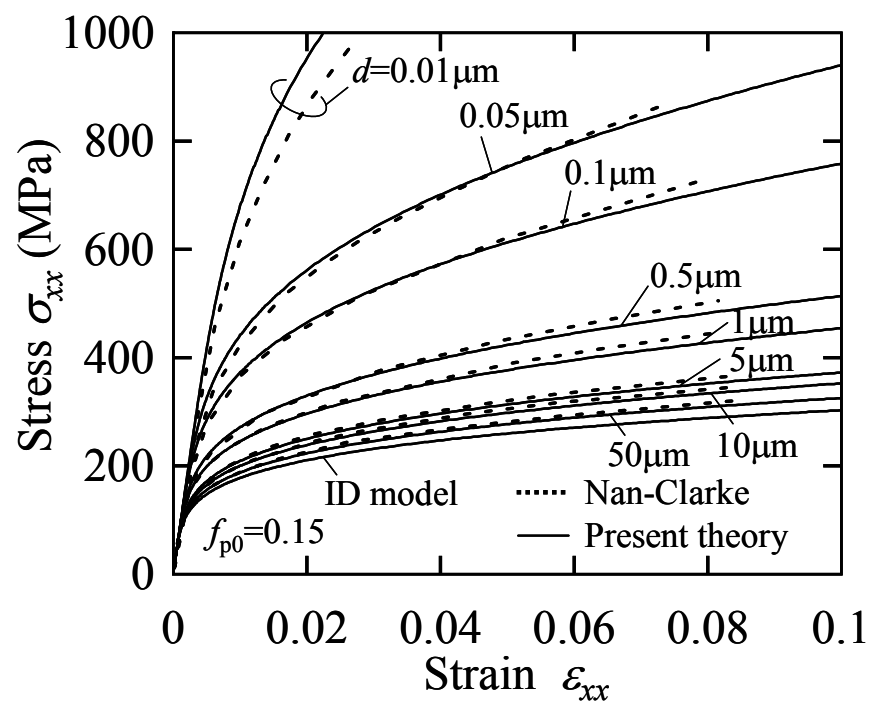

Fig. 3 Particle size effects on stress-strain relations of the composites and comparison between the present model and Nan-Clarke's model.

ID model shows Tohgo-Chou-Weng's model without particle size effects. 


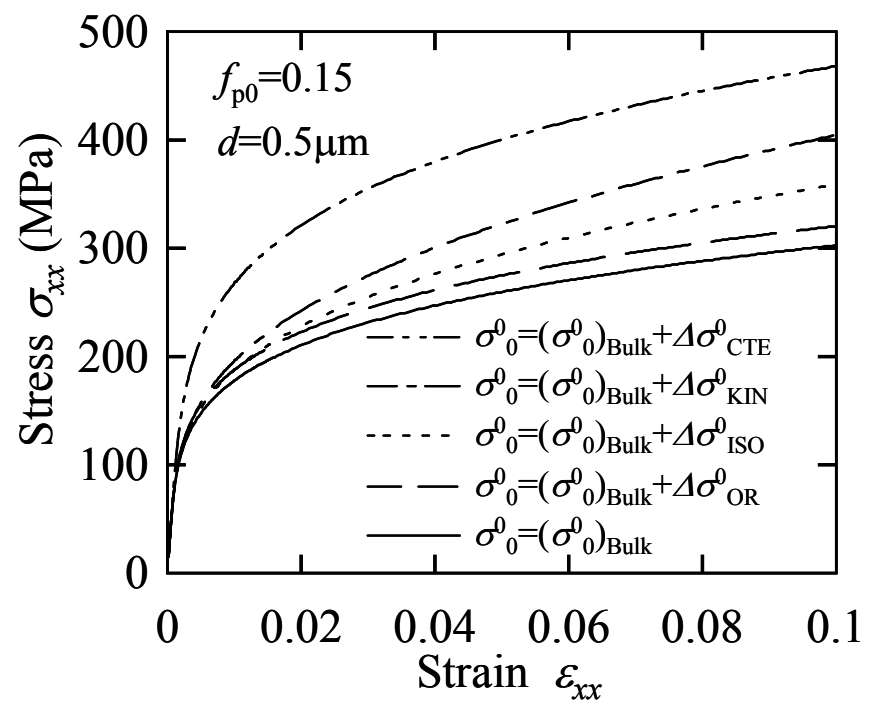

Fig. 4 Influence of each term in dislocation plasticity on stress-strain relation of the composite with particle size of $0.5 \mu \mathrm{m}$.

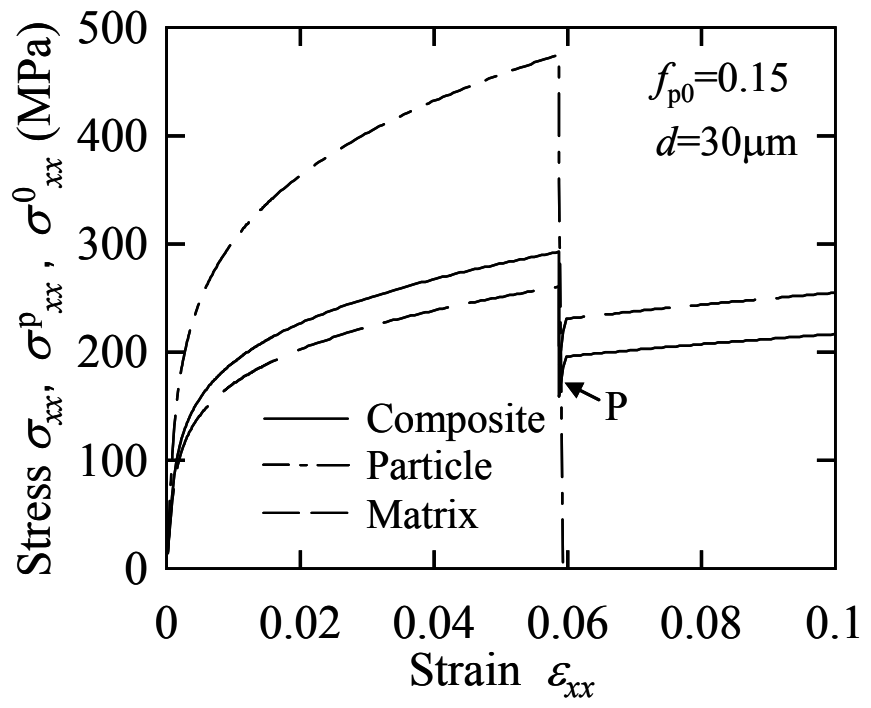

Fig. 5 Composite stress and microscopic stresses of the particles and matrix as functions of composite strain on the composite with debonding damage. 


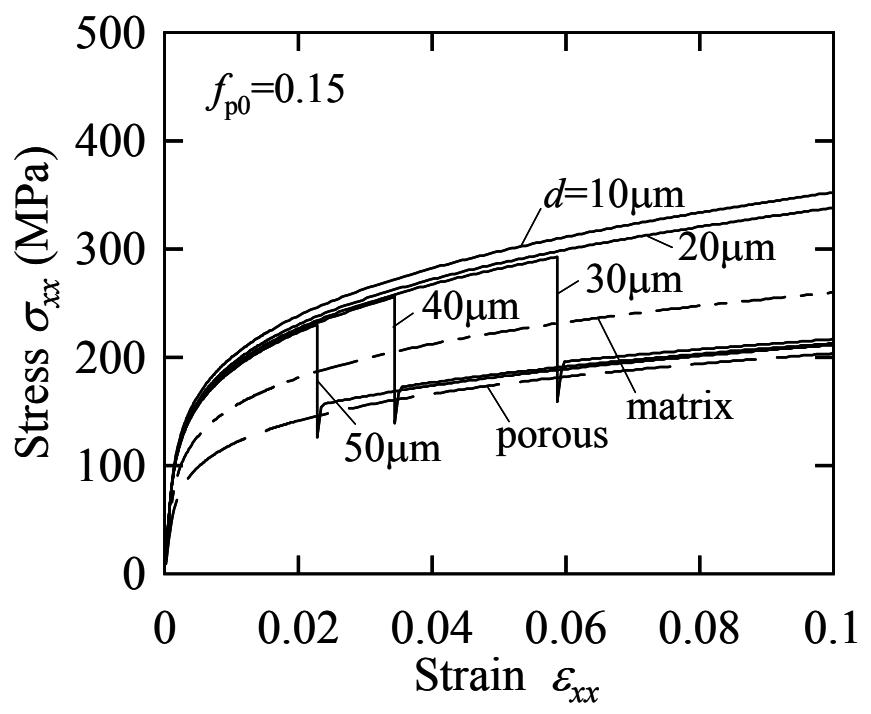

Fig. 6 Particle size effects on stress-strain relation of the composites with debonding damage.

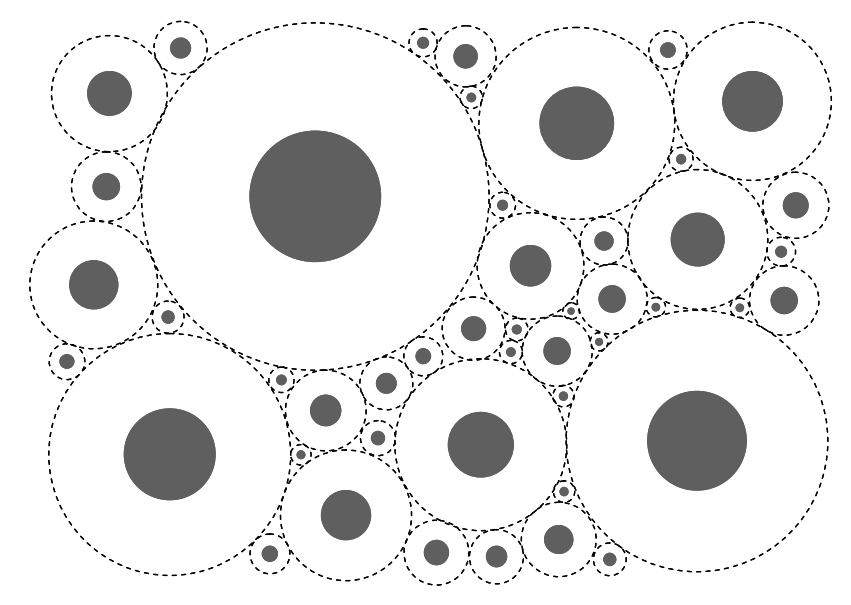

Fig. 7 Composite containing particles with size distribution. 


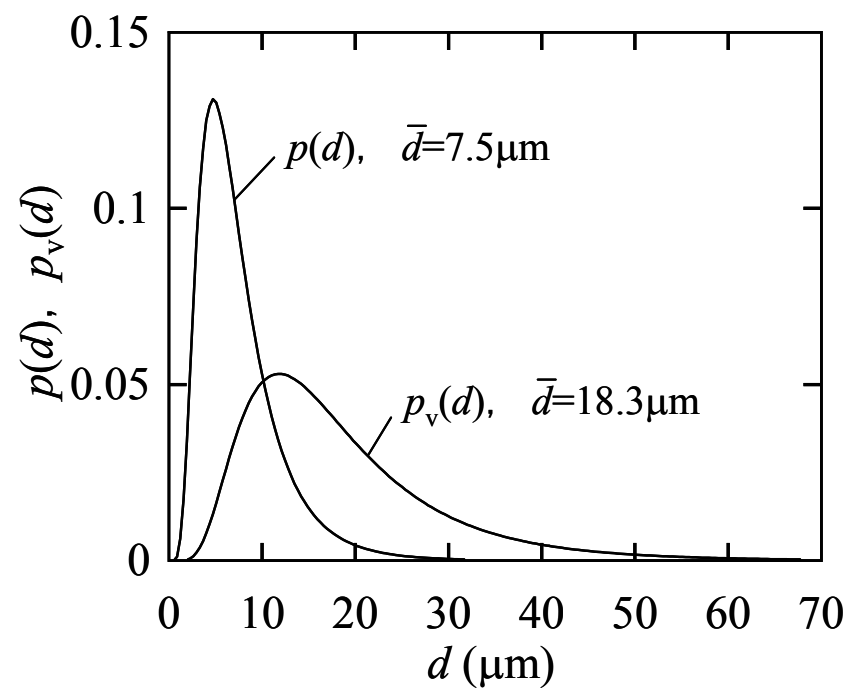

Fig. 8 Lognormal distribution for number frequency $p(d)$ and volume frequency $p_{\mathrm{v}}(d)$ of the particle size distribution.

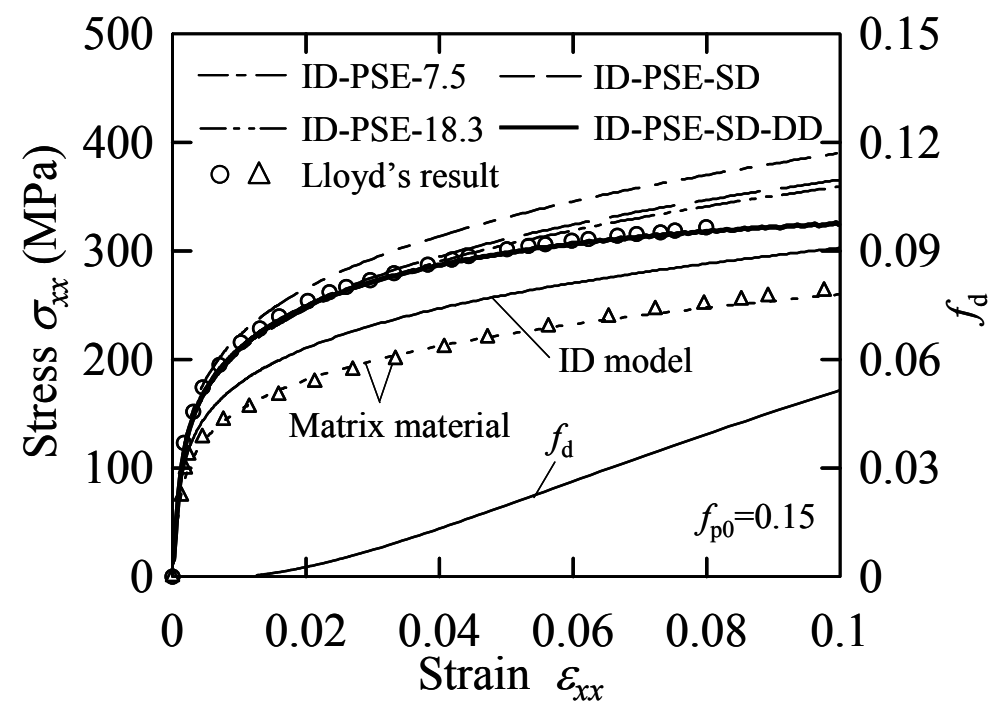

Fig. 9 Comparison of stress-strain relations between the predictions and Lloyd's experimental result for a composite (15vol\% $\mathrm{SiC} / \mathrm{A} 356-\mathrm{T} 4)$.

ID model: Tohgo-Chou-Weng's model.

ID-PSE-7.5 and ID-PSE-18.3: models considering particle size effects for composites with particle size of $7.5 \mu \mathrm{m}$ and $18.3 \mu \mathrm{m}$, respectively.

ID-PSE-SD: a model considering particle size effects and size distribution.

ID-PSE-SD-DD: a model considering particle size effects, size distribution and debonding damage. 


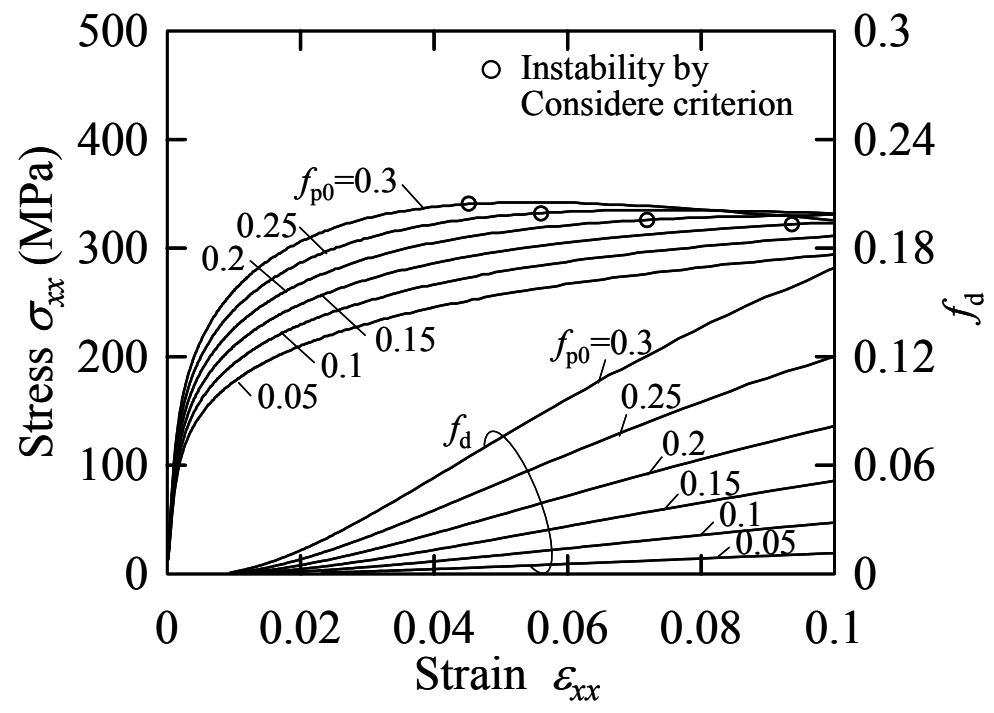

Fig. 10 Influence of particle volume fraction on stress-strain relations and progress of debonding damage of the composites with particle size distribution $(\bar{d}=7.5 \mu \mathrm{m}$ and $\delta=0.55)$ and debonding damage. 